\title{
A multidisciplinaridade na visita domiciliar a idosos: o olhar da Enfermagem, Medicina e Psicologia
}

\section{The multidisciplinariety on the home visit with elderly: the look of Nursing, Medicine and Psychology}

\author{
Ibrahim Clós Mahmud', Carla Viero Kowalski', Bruna Thaíse Lavagnini², Karina Laux Schutz', \\ Claus Dieter Stobäus', Newton Luiz Terra'
}

' Pontifícia Universidade Católica do Rio Grande do Sul (PUCRS). Porto Alegre, RS, Brasil.

2 Especialista em Saúde da Família (UFCSPA). Porto Alegre, RS, Brasil.

\section{ARTICLE INFO}

\section{Article history}

Received: 08/08/2018

Accepted: 09/11/2018

\section{Correspondent Author} Ibrahim Clós Mahmud

Av. Ipiranga, 6690, 70 andar, sala 703

$90610-000$ Porto Alegre, RS, Brasil

(D) orcid.org/0000-0002-2631-2964

<ibrahim_mahmud@hotmail.com>

(C) 2018 All rights reserved

\section{Editors}

Alfredo Cataldo Neto

Paula Engroff

\begin{abstract}
RESUMO
INTRODUÇÃO: O cuidado domiciliar à saúde é uma prática que remonta à própria existência das famílias como unidade de organização social. No Brasil, a assistência domiciliar abrange diversos aspectos, ações de visitas, atendimentos e internações domiciliares. OBJETIVO: Analisar a produção científica da atuação do enfermeiro, do médico e do psicólogo na visita domiciliar de idosos na Atenção Básica no Brasil. MÉTODO: É uma revisão narrativa que usa a ferramenta de busca OMNIS (PUCRS) e utiliza os seguintes descritores: "visita domiciliar" e "idoso" ou "saúde do idoso". Foram incluídos artigos dos últimos 10 anos (2008-2018), revisados por pares e disponíveis em inglês, português ou espanhol. RESULTADOS: encontramos as seguintes publicações: 22 na Enfermagem, 19 em Medicina e 12 em Psicologia. Após a leitura completa dos artigos selecionados e, destes, optou-se pela análise de 10 estudos da área da Enfermagem, 8 da Medicina e 4 da Psicologia. CONCLUSÕES: Foi encontrada pouca literatura diretamente relacionada ao tema no âmbito da Medicina e da Psicologia. Na área da Enfermagem, os artigos foram mais específicos quanto ao papel do enfermeiro na gestão do cuidado.
\end{abstract}

DESCRITORES: visita domiciliar; saúde do idoso; idoso.

\begin{abstract}
INTRODUCTION: Home health care is a practice that goes back to the very existence of families as a unit of social organization. In Brazil, home care covers several aspects, actions of visits, visits and home hospitalizations. OBJECTIVE: To analyze the scientific production of the nurse, doctor and psychologist in the home visit of the elderly in Primary Care in Brazil. METHOD: This is a narrative review using the OMNIS search tool (PUCRS) and uses the following descriptors: "home visit" and "elderly" or "elderly health". We included articles from the last 10 years (2008-2018), peer reviewed and available in English, Portuguese or Spanish. RESULTS: we found the following publications: 22 in Nursing, 19 in Medicine and 12 in Psychology. After the complete reading of the selected articles, we opted for the analysis of 10 studies in the area of Nursing, 8 in Medicine and 4 in Psychology. CONCLUSIONS: There was a lack of scientific material directly related to the subject in Medicine and Psychology. In the area of Nursing, the articles were more specific about the role of nurses in the management of care.

KEYWORDS: house calls; health of the elderly; aged.
\end{abstract}




\section{INTRODUÇÃO}

No âmbito da saúde pública no Brasil, a atenção básica é a porta de entrada dos pacientes ao sistema. Essa porta de entrada deve, portanto, estar preparada e organizada para a atuação adequada, fazendo fluir os problemas e suas resoluções. A atenção básica se caracteriza por ações, tanto individuais quanto coletivas, que abrangem a promoção e proteção da saúde, a prevenção de agravos, o diagnóstico, o tratamento, a reabilitação, a redução de danos e a manutenção da saúde. Objetiva desenvolver uma atenção integral que impacte na situação de saúde e autonomia das pessoas e nos determinantes e condicionantes de saúde da coletividade. ${ }^{1}$

A atenção primária em saúde vem sendo redirecionada, em âmbito nacional, por meio da Estratégia de Saúde da Família (ESF). Em expansão por todo o território brasileiro, a ESF é sistematizada a partir de um conjunto de intervenções multiprofissionais que visam atender às necessidades singulares das famílias e, dessa forma, contribuir para a consolidação dos princípios e das diretrizes do Sistema Único de Saúde (SUS). A mesma é composta por uma equipe multiprofissional com no mínimo: 1 médico, 1 enfermeiro, 3 técnicos de enfermagem e 4 agentes comunitários de saúde. Entre as atividades realizadas pelos profissionais da saúde está a visita domiciliar (VD), que permite conhecer o contexto social e identificar as necessidades individuais e coletivas de saúde da família. ${ }^{1}$

A visita domiciliar é considerada uma importante estratégia de cuidado e educação em saúde pela possibilidade de criar espaços de intersubjetividade e interatividade, que ocorrem por meio do diálogo, da observação e de interpretações significativas. Em sua configuração, a visita domiciliar possibilita, além da compreensão ampliada dos determinantes do processo saúde-doença, desenvolver habilidades de comunicação, de solidariedade e de protagonismo social. ${ }^{2}$

Reconhece-se que o SUS prioriza, cada vez mais, profissionais críticos e reflexivos, capazes de compreenderem as necessidades individuais e coletivas dos indivíduos, bem como intervirem de forma criativa e responsável nos determinantes do processo saúdedoença ${ }^{3}$. Nesse enfoque, a visita domiciliar transcende a assistência fragmentada e pontual e se torna parte de uma Estratégia de Saúde da Família, com caráter sistêmico, inovador e empreendedor.

As competências e habilidades gerais apontam para a atenção à saúde no âmbito individual e coletivo, com integralidade e resolutividade em todos os níveis de complexidade; a tomada de decisões para avaliar, sistematizar e decidir condutas adequadas baseadas em evidências científicas; a comunicação efetiva; a liderança no trabalho multiprofissional, na administração e no gerenciamento da força de trabalho, bem como na educação continuada e permanente.

$\mathrm{Na}$ tentativa de contribuir para a ampliação das discussões acerca das competências e habilidades necessárias para o atendimento domiciliar do enfermeiro, médico e psicólogo com base na saúde vigente, bem como instigar novos saberes que contribuam de forma efetiva e resolutiva para a consolidação da ESF. A escolha por buscar informações sobre o trabalho desses profissionais ocorreu pelo fato de integrarem as equipes de atenção primária, chamadas de Estratégia Saúde da Família (ESF), e o psicólogo fazer parte dos Núcleos de Apoio à Saúde da Família (NASF), que fazem a retaguarda especializada para as equipes de atenção primária, bem como, estarem no mesmo processo de formação do Instituto de Geriatria e Gerontologia da PUCRS.

Sendo assim, o presente estudo tem como objetivo analisar parte da produção científica sobre a atuação desses profissionais na visita domiciliar a idosos na Atenção Básica (AB) no Brasil.

\section{MÉTODO}

Trata-se de estudo de revisão narrativa da literatura. Foi utilizada a ferramenta de busca OMNIS, a qual utiliza o sistema PRIMO, baseado no conceito inovador de "descoberta" que oferece, no resultado da busca, o acesso unificado às informações contidas no acervo das Bibliotecas da PUCRS e em relevantes fontes acadêmicas mundiais composta por 250 bases. A busca procedeu-se no período de abril a maio de 2018, utilizando os seguintes descritores em saúde (DeCS): "saúde do idoso" ou "idoso" e "visita domiciliar". O recorte temporal foi de 2008 a 2018. Para atender aos critérios de inclusão, os artigos deveriam estar disponíveis gratuitamente na íntegra em suporte eletrônico e publicados em periódicos nacionais em português, inglês ou espanhol. Os critérios de exclusão foram: dissertações, teses, capítulos de teses, livros, capítulos de livros, anais de congressos ou conferências, relatórios técnicos e científicos, documentos ministeriais, resumos e artigos que não contemplassem as áreas da saúde solicitadas (enfermagem, medicina e psicologia).

O título e resumo foram descartados naqueles das demais áreas da saúde que não contemplam o objetivo deste trabalho.

Assim, restaram as seguintes publicações: 22 na Enfermagem, 19 em Medicina e 12 em Psicologia. Logo, realizou-se a leitura completa dos artigos selecionados e elaborada a construção de um quadro síntese com os trabalhos mais relevantes escolhidos para análise. Destes, optou-se pela análise de 10 estudos da área da Enfermagem, 8 da Medicina e 4 da Psicologia, descritos na Tabela-Síntese 1. 
Tabela-Síntese 1. Artigos selecionados e analisados

\begin{tabular}{|c|c|c|c|c|c|}
\hline & Objetivos & Conclusões & Revista/Ano & Autores & Método \\
\hline $\mathbf{A}$ & $\begin{array}{l}\text { Identificar as práticas realizadas } \\
\text { pelos profissionais da Estratégia } \\
\text { de Saúde da Família (ESF) } \\
\text { junto aos idosos atendidos em } \\
\text { uma Unidade Básica de Saúde } \\
\text { (UBS). }\end{array}$ & $\begin{array}{l}\text { Para pensar nos significados do } \\
\text { envelhecimento devem-se considerar } \\
\text { as relações dinâmicas que a sociedade } \\
\text { remete ao processo de envelhecer. } \\
\text { É papel do profissional da saúde } \\
\text { assegurar o cuidado integral ao idoso. } \\
\text { Refletir sobre suas práticas de cuidado } \\
\text { garante ao usuário um atendimento } \\
\text { digno e humanizado, compreendendo } \\
\text { o idoso em sua totalidade. }\end{array}$ & $\begin{array}{l}\text { Revista de Pesquisa: Cuidado } \\
\text { é Fundamental Online/ } 2017\end{array}$ & $\begin{array}{l}\text { Amthauer C, } \\
\text { Falk JW }\end{array}$ & $\begin{array}{l}\text { Qualitativo: } \\
\text { entrevista } \\
\text { semiestruturada }\end{array}$ \\
\hline B & $\begin{array}{l}\text { Realizar acompanhamento } \\
\text { domiciliar em idosos de } \\
\text { USF, mensurando o impacto } \\
\text { de medidas, e descrever a } \\
\text { percepção de acadêmicos quanto } \\
\text { ao acompanhamento. }\end{array}$ & $\begin{array}{l}\text { As atividades permitiram o } \\
\text { estabelecimento de vínculo entre a } \\
\text { equipe. O interesse do acadêmico na } \\
\text { atenção à saúde do idoso foi atingido. } \\
\text { A metodologia facilitou o processo de } \\
\text { integração ensino-serviço. }\end{array}$ & $\begin{array}{l}\text { Revista Brasileira de } \\
\text { Educação Médica/ } 2012\end{array}$ & $\begin{array}{l}\text { Boas PJFV, } \\
\text { Souza ML, } \\
\text { Augusto MC, } \\
\text { et al. }\end{array}$ & $\begin{array}{l}\text { Misto: } \\
\text { observação + } \\
\text { estudo } \\
\text { transversal }\end{array}$ \\
\hline C & $\begin{array}{l}\text { Compreender como a visita } \\
\text { domiciliar impacta a prática } \\
\text { médica, com relação a mudanças } \\
\text { na qualidade da interação entre } \\
\text { o professional, o paciente e sua } \\
\text { família. }\end{array}$ & $\begin{array}{l}\text { Percebeu-se que a visita domiciliar } \\
\text { estimula a interação, por favorecer } \\
\text { uma comunicação voltada ao } \\
\text { entendimento mútuo, facilitando } \\
\text { ao profissional compor a busca da } \\
\text { eficácia técnica com a compreensão } \\
\text { e foco nos projetos de felicidade dos } \\
\text { pacientes e familiares. }\end{array}$ & $\begin{array}{l}\text { Interface - Comunicação, } \\
\text { Saúde, Educação/2011 }\end{array}$ & $\begin{array}{l}\text { Borges R, } \\
\text { D'Oliveira AFPL }\end{array}$ & $\begin{array}{l}\text { Qualitativo: } \\
\text { triangulação } \\
\text { de técnicas } \\
\text { (observação, } \\
\text { entrevista } \\
\text { e leitura de } \\
\text { documentos) }\end{array}$ \\
\hline D & $\begin{array}{l}\text { Descrever a experiência de } \\
\text { preparação de alunos do } \\
\text { primeiro ano da Faculdade de } \\
\text { Medicina de Botucatu-Unesp. }\end{array}$ & $\begin{array}{l}\text { Esta experiência reforça a } \\
\text { necessidade de preparar o graduando } \\
\text { para entrar em contato com os } \\
\text { múltiplos e complexos determinantes } \\
\text { do processo saúde-doença e para } \\
\text { atuar no cuidado à saúde segundo } \\
\text { uma perspectiva interdisciplinar e } \\
\text { intersetorial. }\end{array}$ & $\begin{array}{l}\text { Revista Brasileira de } \\
\text { Educação Médica/ } 2009\end{array}$ & $\begin{array}{l}\text { Cerqueira ATAR, } \\
\text { Torres AR, } \\
\text { Martins STF, } \\
\text { et al. }\end{array}$ & $\begin{array}{l}\text { Qualitativo: } \\
\text { vivência } \\
\text { sociodramática }\end{array}$ \\
\hline $\mathbf{E}$ & $\begin{array}{l}\text { Compreender a construção } \\
\text { do cuidado no Programa de } \\
\text { Atendimento Domiciliar ao } \\
\text { Acamado (PADA) de uma } \\
\text { unidade básica de saúde (UBS) } \\
\text { em Porto Alegre, RS. }\end{array}$ & $\begin{array}{l}\text { O cuidado como direito de cidadania } \\
\text { em contraposição ao cuidado como } \\
\text { submissão e assujeitamento tensionou } \\
\text { o grupo. O cuidado compreende } \\
\text { uma síntese entre o exercício de uma } \\
\text { pessoa sobre ela mesma, tornando-a } \\
\text { melhor como ser humano e, ao } \\
\text { mesmo tempo, capacitando-a a se } \\
\text { tornar melhor como cidadão. }\end{array}$ & $\begin{array}{l}\text { Ciência \& Saúde } \\
\text { Coletiva/2011 }\end{array}$ & $\begin{array}{l}\text { Freitas IBA, } \\
\text { Meneghel ST, } \\
\text { Selli L }\end{array}$ & $\begin{array}{l}\text { Qualitativo: } \\
\text { estudo de caso }\end{array}$ \\
\hline $\mathbf{F}$ & $\begin{array}{l}\text { Descrever os aspectos que } \\
\text { envolvem a elegibilidade, } \\
\text { inclusão, exclusão e alta } \\
\text { na atenção domiciliar na } \\
\text { perspectiva de gestores e } \\
\text { coordenadores de atenção } \\
\text { domiciliar. }\end{array}$ & $\begin{array}{l}\text { Embora os critérios dos serviços } \\
\text { de assistência domiciliar estejam } \\
\text { definidos pelo Ministério da } \\
\text { Saúde, os gestores e coordenadores } \\
\text { abrem exceções na inclusão e alta } \\
\text { considerando: a fragilidade da rede } \\
\text { para alta e encaminhamento para } \\
\text { outro ponto de atenção e a realidade } \\
\text { do paciente. A atenção domiciliar } \\
\text { deve ser realizada quando as } \\
\text { condições clínicas e administrativas } \\
\text { do usuário permitam, considerando } \\
\text { os critérios de elegibilidade, inclusão, } \\
\text { exclusão e alta. }\end{array}$ & $\begin{array}{l}\text { Revista Brasileira Promoção } \\
\text { da Saúde/ } 2016\end{array}$ & $\begin{array}{l}\text { Paiva PA, } \\
\text { Silva YC, } \\
\text { Soares NF, } \\
\text { et al. }\end{array}$ & $\begin{array}{l}\text { Qualitativo: } \\
\text { descritivo } \\
\text { exploratório }\end{array}$ \\
\hline G & $\begin{array}{l}\text { Relatar caso: descrevendo a } \\
\text { gestão de cuidados ao idoso } \\
\text { dependente. }\end{array}$ & $\begin{array}{l}\text { A relevância deste caso prende-se } \\
\text { com o fato de constituir um exemplo } \\
\text { paradigmático da atividade distintiva } \\
\text { do médico de família, enquanto } \\
\text { agente executor de uma abordagem } \\
\text { globalizante, capaz de aglutinar os } \\
\text { múltiplos aspectos fundamentais ao } \\
\text { bem-estar integral dos doentes. }\end{array}$ & $\begin{array}{l}\text { Revista Brasileira } \\
\text { Medicina de Familia e } \\
\text { Comunidade/2016 }\end{array}$ & Teixeira D & $\begin{array}{l}\text { Quantitativo: } \\
\text { relato de caso }\end{array}$ \\
\hline
\end{tabular}


Tabela-Síntese 1 (continuação)

\begin{tabular}{|c|c|c|c|c|c|}
\hline & Objetivos & Conclusões & Revista/Ano & Autores & Método \\
\hline $\mathbf{H}$ & $\begin{array}{l}\text { Investigar proposta de VD na } \\
\text { formação medico, utilizando } \\
\text { pesquisa documental. }\end{array}$ & $\begin{array}{l}\text { Concluiu-se que a VD pode fortalecer } \\
\text { e ampliar vínculos, compromissos, } \\
\text { e favorecer a comunicação, } \\
\text { contribuindo para a mudança da } \\
\text { educação médica no Brasil. }\end{array}$ & $\begin{array}{l}\text { Interface - Comunicação, } \\
\text { Saúde, Educação/2012 }\end{array}$ & $\begin{array}{l}\text { Romanholi RMZ } \\
\text { Cyrino EG }\end{array}$ & $\begin{array}{l}\text { Qualitativo: } \\
\text { estudo de caso }\end{array}$ \\
\hline I & $\begin{array}{l}\text { Identificar, na ótica do cuidador, } \\
\text { mudanças ocorridas nas relações } \\
\text { familiares após evento gerador } \\
\text { de dependência no idoso e os } \\
\text { fatores causadores. }\end{array}$ & $\begin{array}{l}\text { A união familiar preexistente à } \\
\text { dependência predispõe alterações } \\
\text { positivas, favorecida com suporte } \\
\text { formal e informal. A sobrecarga do } \\
\text { cuidador familiar, por falta de apoio, } \\
\text { pela idade e atividades do cuidador, } \\
\text { leva a situações negativas na família. } \\
\text { A efetividade das políticas públicas } \\
\text { para prestar suporte formal aos idosos } \\
\text { e seus cuidadores, e a criação de } \\
\text { grupos de apoio, podem contribuir no } \\
\text { bem estar da família. }\end{array}$ & $\begin{array}{l}\text { Revista Brasileira de } \\
\text { Enfermagem } / 2012\end{array}$ & $\begin{array}{l}\text { Pedreira LC, } \\
\text { Oliveira AMS }\end{array}$ & $\begin{array}{l}\text { Qualitativo: } \\
\text { estudo de campo }\end{array}$ \\
\hline $\mathbf{J}$ & $\begin{array}{l}\text { Avaliar fatores associados à } \\
\text { assistência domiciliar recebida } \\
\text { pela população idosa e suas } \\
\text { características, segundo modelos } \\
\text { de atenção Estratégia Saúde da } \\
\text { Família e modelo tradicional. }\end{array}$ & $\begin{array}{l}\text { As variáveis associadas ao } \\
\text { recebimento de assistência domiciliar } \\
\text { reiteram os indicadores de fragilidade } \\
\text { destacados na Política Nacional de } \\
\text { Saúde da Pessoa Idosa e fortalecem } \\
\text { a importância da estratégia na } \\
\text { promoção da eqüidade no cuidado } \\
\text { dos idosos. A avaliação positiva } \\
\text { e o impacto na situção de saúde } \\
\text { afirmam o domicílio como ambiente } \\
\text { terapêutico. }\end{array}$ & Revista Saúde Pública/2010 & $\begin{array}{l}\text { Thume E, } \\
\text { Facchini LA, } \\
\text { Tomasi E, } \\
\text { et al. }\end{array}$ & $\begin{array}{l}\text { Quantitativo: } \\
\text { transversal } \\
\text { de base } \\
\text { populacional }\end{array}$ \\
\hline $\mathbf{K}$ & $\begin{array}{l}\text { Oferecer aos cuidadores de } \\
\text { pacientes paliativos um espaço } \\
\text { para ouvi-los e acompanhá- } \\
\text { los, reforçando as importantes } \\
\text { contribuições da psicologia } \\
\text { nesse contexto. }\end{array}$ & $\begin{array}{l}\text { Devido à experiência durante as } \\
\text { visitas do estágio, pudemos perceber } \\
\text { a importância do papel do psicólogo } \\
\text { na VD uma vez que é notável o } \\
\text { sofrimento do cuidador perante o } \\
\text { exercício do cuidado do paciente, } \\
\text { não apenas pela doença, mas também } \\
\text { pelo processo que impacta a dinâmica } \\
\text { familiar, as mudanças repentinas e a } \\
\text { necessidade de dedicação a outra vida } \\
\text { e o quanto isso pode afetar a vida dos } \\
\text { cuidadores. }\end{array}$ & Revista Saúde em Foco/2017 & $\begin{array}{l}\text { Faria AA, } \\
\text { Aparecido AM, } \\
\text { Cruz GL, } \\
\text { et al. }\end{array}$ & $\begin{array}{l}\text { Qualitativo: } \\
\text { estudo de campo }\end{array}$ \\
\hline $\mathbf{L}$ & $\begin{array}{l}\text { descrever a Visita Domiciliar e a } \\
\text { função do(a) psicólogo(a) nesse } \\
\text { contexto a partir das vivências } \\
\text { práticas das estagiárias e da } \\
\text { supervisora em um programa } \\
\text { de Visita Domiciliar implantado } \\
\text { no curso de psicologia de uma } \\
\text { universidade privada da cidade } \\
\text { de São Paulo. }\end{array}$ & $\begin{array}{l}\text { O trabalho do psicólogo na Visita } \\
\text { Domiciliar ultrapassa as fronteiras e } \\
\text { limites presentes na clínica, fazendo- } \\
\text { se necessário um olhar diferenciado } \\
\text { sobre sua atuação, considerando o } \\
\text { sujeito como um todo em seu âmbito } \\
\text { familiar e coletivo. Está posto o } \\
\text { desafio, em que pese o diálogo entre } \\
\text { as políticas públicas de educação } \\
\text { (formação profissional) e de saúde } \\
\text { (ampliação da demanda por atuação } \\
\text { junto à comunidade) no âmbito da } \\
\text { prevenção e promoção de saúde. }\end{array}$ & $\begin{array}{l}\text { Revista Gestão \& Políticas } \\
\text { Públicas/2015 }\end{array}$ & $\begin{array}{l}\text { Aron ML, } \\
\text { Santos NCD }\end{array}$ & $\begin{array}{l}\text { Qualitativo: } \\
\text { estudo de campo }\end{array}$ \\
\hline M & $\begin{array}{l}\text { reflexão teórica sobre a presença } \\
\text { dos atributos essenciais da APS } \\
\text { na ESF. }\end{array}$ & $\begin{array}{l}\text { A efetividade da política de saúde } \\
\text { não depende apenas das diretrizes } \\
\text { que emanam do arcabouço jurídico- } \\
\text { institucional, mas será garantida com } \\
\text { a reafirmação contundente de um } \\
\text { sistema público de saúde socialmente } \\
\text { superior ao modelo liberal ou médico } \\
\text { tradicional, que somente a luta } \\
\text { constante dos movimentos sociais } \\
\text { pelo direito à saúde pode garantir. }\end{array}$ & $\begin{array}{l}\text { Revista Brasileira } \\
\text { Enfermagem } / 2013\end{array}$ & $\begin{array}{l}\text { Oliveira MAC, } \\
\text { Pereira IC, }\end{array}$ & $\begin{array}{l}\text { Qualitativo: } \\
\text { estudo de campo }\end{array}$ \\
\hline
\end{tabular}


Tabela-Síntese 1 (continuação)

\begin{tabular}{|c|c|c|c|c|c|}
\hline & Objetivos & Conclusões & Revista/Ano & Autores & Método \\
\hline $\mathbf{N}$ & $\begin{array}{l}\text { relatar a vivência de } \\
\text { ensino-aprendizagem vinculada } \\
\text { a um projeto ampliado de } \\
\text { ensino, pesquisa e extensão } \\
\text { fundamentado nas teorias de } \\
\text { enfermagem. }\end{array}$ & $\begin{array}{l}\text { Instigar o protagonismo e } \\
\text { empreendedorismo social na } \\
\text { formação, a partir das teorias de } \\
\text { enfermagem, significa desenvolver } \\
\text { um conhecimento capaz de dialogar } \\
\text { e integrar os diferentes saberes, } \\
\text { pelo desenvolvimento de práticas } \\
\text { em consonância com o exercício } \\
\text { da cidadania e transformação } \\
\text { social. }\end{array}$ & Escola Anna Nery/2012 & $\begin{array}{l}\text { Backes DS, } \\
\text { Grando MK, } \\
\text { Gracioli MA, } \\
\text { et al. }\end{array}$ & $\begin{array}{l}\text { Qualitativo: } \\
\text { descritivo } \\
\text { exploratório }\end{array}$ \\
\hline $\mathbf{O}$ & $\begin{array}{l}\text { contribuir para a construção } \\
\text { de conhecimento em relação } \\
\text { aoVD, a partir da trajetória } \\
\text { histórica do conceito; seguimos } \\
\text { evidenciando suas possibilidades } \\
\text { como tecnologia para o cuidado, } \\
\text { o ensino e a pesquisa. }\end{array}$ & $\begin{array}{l}\text { O resgate histórico da visita } \\
\text { domiciliar como tecnologia } \\
\text { leve-dura de ampla utilização na } \\
\text { área da saúde, detectou a } \\
\text { necessidade de desenvolvimento } \\
\text { de estudos que ofereçam maior } \\
\text { suporte científico, tanto conceitual } \\
\text { metodológico. Sua indicação } \\
\text { enquanto método, tanto educacional } \\
\text { (formação dos profissionais e } \\
\text { educação em saúde) quanto de } \\
\text { assistência (diagnóstico de } \\
\text { demandas e cuidados das pessoas } \\
\text { e famílias) e pesquisa (investigação } \\
\text { e avaliação de programas junto à } \\
\text { comunidade), evidencia a } \\
\text { importância de sistematização e } \\
\text { divulgação dos resultados } \\
\text { obtidos }\end{array}$ & $\begin{array}{l}\text { Ciência, Cuidado e } \\
\text { Saúde/2008 }\end{array}$ & $\begin{array}{l}\text { Lopes WO, } \\
\text { Saupe R, } \\
\text { Massaroli A }\end{array}$ & $\begin{array}{l}\text { Qualitativo: } \\
\text { revisão } \\
\text { bibliográfica }\end{array}$ \\
\hline $\mathbf{P}$ & $\begin{array}{l}\text { compreender os significados } \\
\text { atribuídos por famílias à visita } \\
\text { domiciliária realizada pela } \\
\text { Estratégia Saúde da Família } \\
\text { (ESF), com a intenção de } \\
\text { reconhecer as dificuldades e } \\
\text { potencialidades dessa prática. }\end{array}$ & $\begin{array}{l}\text { A VD, quando realizada } \\
\text { adequadamente, é uma das ações } \\
\text { que pode facilitar a compreensão e } \\
\text { o cuidado às famílias atendidas ao } \\
\text { propiciar o conhecimento de seus } \\
\text { modos de vida, crenças, cultura } \\
\text { e padrões de comportamento, } \\
\text { permitindo incorporar tecnologias } \\
\text { leves no cuidado, como a } \\
\text { humanização. Nesse sentido, os } \\
\text { posicionamentos encontrados } \\
\text { remetem à reflexão em torno das } \\
\text { potencialidades e limitações dessa } \\
\text { prática, considerando que além de } \\
\text { reafirmarem uma dada perspectiva } \\
\text { de direitos também refletem e } \\
\text { reforçam o perfil tradicional das } \\
\text { práticas em saúde que se busca } \\
\text { modificar. }\end{array}$ & Saúde e Sociedade/2010 & $\begin{array}{l}\text { Cruz MM, } \\
\text { Bourget MM }\end{array}$ & $\begin{array}{l}\text { Qualitativo: } \\
\text { estudo de campo }\end{array}$ \\
\hline $\mathbf{Q}$ & $\begin{array}{l}\text { O objetivo deste estudo é } \\
\text { identificar os aspectos abordados } \\
\text { sobre a formação para o cuidado } \\
\text { domiciliar-CD nas produções } \\
\text { científicas brasileiras }\end{array}$ & $\begin{array}{l}\text { O cuidado domiciliar tem } \\
\text { especificidades que devem ser } \\
\text { aprendidas durante a graduação } \\
\text { em Enfermagem, para que a } \\
\text { enfermeira possa realmente } \\
\text { transpor a barreira do cuidado } \\
\text { mecanicista que foi e ainda é } \\
\text { largamente ensinado, mas que tem } \\
\text { recebido inúmeras críticas nos } \\
\text { últimos anos. Evidencia-se que são } \\
\text { muitas as competências exigidas da } \\
\text { enfermeira ao atuar no domicílio, } \\
\text { que não podem ser aprendidas } \\
\text { apenas na prática e sim durante a } \\
\text { sua formação profissional. }\end{array}$ & Revista Cogitare/2009 & $\begin{array}{l}\text { Hermann A, } \\
\text { Marineli M, } \\
\text { Wall ML, } \\
\text { Bernardino E, } \\
\text { Lacerda MR }\end{array}$ & $\begin{array}{l}\text { Qualitativo: } \\
\text { revisão } \\
\text { integrativa }\end{array}$ \\
\hline
\end{tabular}


Tabela-Síntese 1 (continuação)

\begin{tabular}{|c|c|c|c|c|c|}
\hline & Objetivos & Conclusões & Revista/Ano & Autores & Método \\
\hline $\mathbf{R}$ & $\begin{array}{l}\text { Refletir de que forma a atenção } \\
\text { domiciliária tem contribuído } \\
\text { para a saúde da população }\end{array}$ & $\begin{array}{l}\text { A atenção domiciliária tem sido } \\
\text { realizada com foco na doença, } \\
\text { tem como objeto de trabalho um } \\
\text { sujeito individual, enfatiza } \\
\text { o cuidado curativo e não } \\
\text { desenvolve ações intersetoriais. } \\
\text { Porém, busca resolutividade no } \\
\text { primeiro contato, presta atenção } \\
\text { contínua e longitudinal, tem } \\
\text { território definido, promove as } \\
\text { relações interpessoais (trabalhadores } \\
\text { e usuários) e atua visando um } \\
\text { cuidado humanizado. }\end{array}$ & $\begin{array}{l}\text { Acta Paulista } \\
\text { Enfermagem } / 2010\end{array}$ & $\begin{array}{l}\text { Kerber NPC, } \\
\text { Kirchhof ALC, } \\
\text { Cezar-Vaz MR }\end{array}$ & $\begin{array}{l}\text { Qualitativo: } \\
\text { estudo de caso }\end{array}$ \\
\hline $\mathbf{S}$ & $\begin{array}{l}\text { identificar os aspectos de maior } \\
\text { relevância sobre o cuidado } \\
\text { domiciliar presentes nas } \\
\text { pesquisas científicas brasileiras. }\end{array}$ & $\begin{array}{l}\text { Fica evidente que o diferencial } \\
\text { do cuidado domiciliar é o aspecto } \\
\text { humano, no sentido de primar } \\
\text { pela qualidade de vida do cliente } \\
\text { quando este permanece em seu } \\
\text { lar, com familiares e amigos. Ao } \\
\text { mesmo tempo em que cumpre seu } \\
\text { papel, é atendido por profissionais } \\
\text { capacitados e preparados para } \\
\text { enfrentar as particularidades do } \\
\text { domicílio e do cuidado realizado } \\
\text { nesse local. }\end{array}$ & $\begin{array}{l}\text { Revista Mineira de } \\
\text { Enfermagem/2009 }\end{array}$ & $\begin{array}{l}\text { Favero.L } \\
\text { Lacerda.ML } \\
\text { Mazza.VM } \\
\text { Hermann. AP }\end{array}$ & $\begin{array}{l}\text { Qualitativo: } \\
\text { revisão } \\
\text { integrativa }\end{array}$ \\
\hline $\mathbf{T}$ & $\begin{array}{l}\text { compreender as concepções } \\
\text { da equipe de Saúde da Família } \\
\text { sobre as visitas }\end{array}$ & $\begin{array}{l}\text { A concepção que os profissionais } \\
\text { das equipes de Saúde da Família } \\
\text { têm sobre as visitas domiciliares, } \\
\text { evidencia que as mesmas são } \\
\text { atividades potenciais para se } \\
\text { utilizar tecnologias leves e } \\
\text { proporcionar novos modos de se } \\
\text { cuidar na saúde: mais humanos e } \\
\text { acolhedores, envolvendo afetividade } \\
\text { e laços de confiança entre os } \\
\text { profissionais, os usuários, a família } \\
\text { e a comunidade. }\end{array}$ & $\begin{array}{l}\text { Revista Brasileira } \\
\text { Enfermagem } / 2008\end{array}$ & $\begin{array}{l}\text { Sakata KN, } \\
\text { Almeida MCP, } \\
\text { Alvarenga AM, } \\
\text { et al. }\end{array}$ & $\begin{array}{l}\text { Qualitativo: } \\
\text { estudo de campo }\end{array}$ \\
\hline $\mathbf{U}$ & $\begin{array}{l}\text { Analisar práticas de atenção } \\
\text { domiciliar de serviços } \\
\text { ambulatoriais e hospitalares } \\
\text { e sua constituição como rede } \\
\text { substitutiva de cuidado em } \\
\text { saúde }\end{array}$ & $\begin{array}{l}\text { A atenção domiciliar possui } \\
\text { potencial para constituição de uma } \\
\text { rede substitutiva ao produzir novos } \\
\text { modos de cuidar que atravessam os } \\
\text { projetos dos usuários, dos familiares, } \\
\text { da rede social e dos trabalhadores } \\
\text { da atenção domiciliar. A atenção } \\
\text { domiciliar como modalidade } \\
\text { substitutiva de atenção à saúde } \\
\text { requer sustentabilidade política, } \\
\text { conceitual e operacional, bem } \\
\text { como reconhecimento dos novos } \\
\text { arranjos e articulação das propostas } \\
\text { em curso. }\end{array}$ & Revista Saúde Pública/2010 & $\begin{array}{l}\text { Silva KL, } \\
\text { Sena RR, } \\
\text { Seixas CT, } \\
\text { et al. }\end{array}$ & $\begin{array}{l}\text { Qualitativo: } \\
\text { estudo de campo }\end{array}$ \\
\hline $\mathbf{V}$ & $\begin{array}{l}\text { descrever a visita domiciliar } \\
\text { a partir de uma leitura crítico- } \\
\text { reflexiva da bibliografia sobre } \\
\text { a temática, tendo como foco o } \\
\text { debate histórico-político }\end{array}$ & $\begin{array}{l}\text { A assistência domiciliar é uma } \\
\text { modalidade cada vez mais } \\
\text { presente em nossa realidade. A VD } \\
\text { potencializa e expande o alcance } \\
\text { desta prática, permitindo maior } \\
\text { integração entre as ações que } \\
\text { acontecem no domicílio e as que } \\
\text { ocorrem no interior dos serviços de } \\
\text { saúde. É uma estratégia fundamental } \\
\text { para a construção de um sistema de } \\
\text { saúde realmente único, integral e } \\
\text { equânime. }\end{array}$ & Revista APS/2011 & Abrahão LA & $\begin{array}{l}\text { Qualitativo: } \\
\text { estudo de caso }\end{array}$ \\
\hline
\end{tabular}




\section{RESULTADOS}

Esse estudo contou com a leitura na íntegra dos trabalhos publicados dentro da temática da visita domiciliar a idosos, optou-se pela análise de 10 estudos da área da Enfermagem, 8 da Medicina e 4 da Psicologia, descritos na Tabela-Síntese 1.

$\mathrm{Na}$ perspectiva do profissional médico os artigos identificados com as letras $\mathrm{A}, \mathrm{B}, \mathrm{C}, \mathrm{D}, \mathrm{E}, \mathrm{F}$ valoriza o trabalho da equipe multiprofissional reconhecendo como uma modalidade de atenção à saúde coletiva que se configura na relação recíproca entre as múltiplas intervenções técnicas e a interação nas diferentes áreas profissionais. $\mathrm{O}$ papel da VD, com ênfase na atenção ao idoso, se destaca pela identificação dos agravos mais frequentes e sua intervenção. Tornando o papel do médico imprescindível durante a VD. Em suma é papel do profissional da saúde assegurar o cuidado integral ao idoso (letras $\mathbf{R}, \mathrm{S}, \mathrm{T}$ ). Refletir sobre suas práticas de cuidado garantindo ao usuário um atendimento digno e humanizado, compreendendo o idoso em sua totalidade e especificidade dentro do contexto o qual habita.

No contexto do profissional na enfermagem a leitura realizada indica que o enfermeiro também ocupa papel central durante a VD. Os artigos identificados pelas letras $\mathrm{G}, \mathrm{H}, \mathrm{I}, \mathrm{J}, \mathrm{I}$ reforçam a relevância da atuação do enfermeiro perpassa por seu preparo através da formação acadêmica voltada a essa experiência. A literatura evidencia o papel fundamental do enfermeiro na construção deste tipo de cuidado e amplia as discussões ao defender que a visita domiciliar favorece o cuidado humano, criativo, sensível e longe da internação hospitalar.

Sabe-se que a atuação na VD é influenciada pelo vinculo estipulado entre paciente-enfermeiro. A revisão dos artigos revelou que enfermeiros realizam ações diversificadas na VD, tais como: apoio interpessoal, educação em saúde realização de procedimentos técnicos.

Os outros estudos (letras $\mathbf{K}, \mathbf{L}, \mathbf{M}, \mathbf{P}$ ) reiteram que a ESF pressupõe a visita domiciliar como tecnologia de interação no cuidado à saúde em diversas áreas. O mesmo sinaliza o lugar da dimensão intersubjetiva, uma vez que o sucesso das práticas em saúde depende não apenas do componente técnico, mas de outras tecnologias baseadas na aproximação, no diálogo e na vinculação entre profissionais, usuários e serviços. Dentro desse contexto o profissional psicólogo por meio do NASF vem com o objetivo de sanar lacunas e complementar o cuidado/atendimento ao paciente (letras $\mathrm{N}, \mathrm{O}, \mathrm{Q}$ ). Embora a VD seja uma pratica relativamente nova proporcionar essa experiência in loco, é um dos principais efeitos gerados pela prática da visita domiciliar em uma perspectiva psicossocial quanto à formação de profissionais, comprometidos com atuação principalmente aos segmentos mais vulnerabilizados da sociedade.

\section{DISCUSSÃO}

Após uma análise dos principais artigos que tratam dessa realidade, pode-se identificar e agrupar a temática em três tópicos: A inserção do enfermeiro na Visita Domiciliar; A Visita Domiciliar como espaço que permite a construção de estratégias e ações de cuidado; A Importância do médico durante a visita domiciliar; O olhar da psicologia na Visita domiciliar, destacados por Cunha ${ }^{4}$, na Figura 1.

Com vistas a dar atenção ao paciente com dificuldades temporárias ou definitivas, seja por barreira geográfica, doença crônica degenerativa ou em recuperação de algum acidente, no contexto da Atenção Primária, a atenção domiciliar vem sendo cada vez mais necessária devido às mudanças que vão ocorrendo com a própria população, a fim de garantir equidade. Logo, necessita estar inserida no sistema de formação e/ou capacitação dos profissionais de saúde de distintas especialidades, ampliando a prática dessa atenção.

Considerando que dentro da atenção domiciliar existem diferentes modalidades e que cada uma tem suas diferenças em abordagem e percepção, devemos ter claro o que cada uma representa na prática para, assim, ter mais êxito na realização dos objetivos. ${ }^{4}$

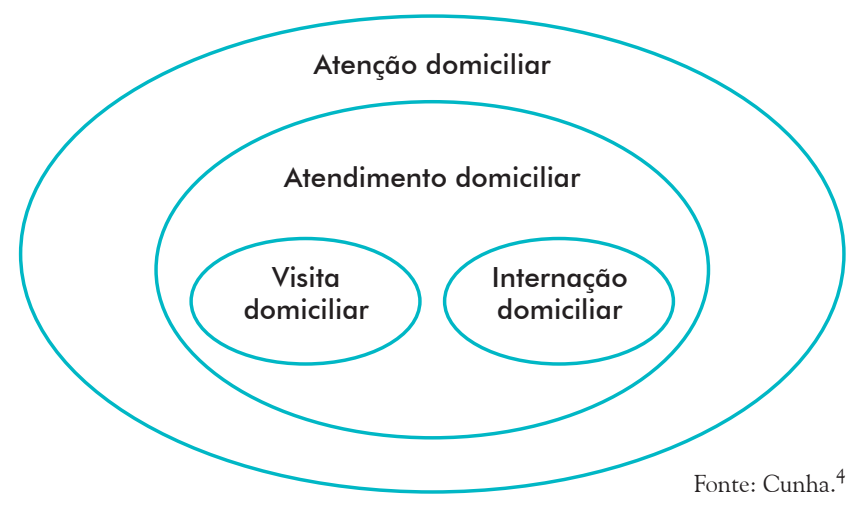

Figura 1. Representação esquemática da atenção à saúde domiciliar e suas respectivas modalidades

Essas modalidades podem ser definidas desta forma: ${ }^{4}$

- Atenção Domiciliar (AD) : é uma modalidade de maior amplitude que envolve ações de promoção, prevenção, tratamento e reabilitação desenvolvidas por uma equipe multiprofissional no domicílio do paciente, juntamente com sua família ${ }^{4}$. 
- Atendimento Domiciliar: é sinônimo de assistência ou cuidado domiciliar caracterizado por atividades programadas e continuadas de caráter ambulatorial realizadas no domicílio, no caso de indivíduos em circunstâncias agudas ou crônicas que recebem tratamento de alta qualidade. ${ }^{4}$

- Internação Domiciliar: atividade que oferta tecnologia, equipamentos e materiais, supervisão e ação da equipe de saúde, com uma assistência semelhante à hospitalar. ${ }^{4}$

- Visita Domiciliar (VD): útil para orientar, educar e desenvolver soluções para os problemas de saúde, além de orientar sobre o uso de medicamentos, saneamento básico e tudo que diz respeito à condição de saúde. É um contato pontual dos profissionais de saúde com a comunidade, assim diferenciando-se da $\mathrm{AD}$, que possui uma longitudinalidade do cuidado. ${ }^{4}$

Para eleger um paciente ou uma família para a atenção domiciliar, alguns critérios são considerados: critérios clínicos (situação do paciente) e critérios administrativos (administrativos/operacionais/legais). Apesar disso, a forma crítica de avaliar a realidade cotidiana é um dos principais critérios. Por sua vez, a atenção domiciliar está organizada em três modalidades de acordo com o perfil do usuário e a equipe prestadora de cuidado: AD1, AD2, AD333, conforme descrito no Quadro 1.

O Programa Melhor em Casa, criado em 2001, oferta o serviço de internação domiciliar, em que duas equipes atuam: a Equipe Multiprofissional de Atenção Domiciliar (EMAD) e a Equipe Multiprofissional de Apoio (EMAP) ${ }^{5}$. A EMAD contempla uma equipe básica de internação domiciliar, com técnicos de enfermagem, enfermeiro, médico e fisioterapeuta. Já a EMAP deve ser constituída de no mínimo 3 profissionais dentre estes: assistente social, fisioterapeuta, fonoaudiólogo, nutricionista, odontólogo, psicólogo, farmacêutico e terapeuta ocupacional. Para a implementação desse programa, necessitam-se de outros critérios:

A EMAD deverá atender a uma população adstrita de 100 mil habitantes, com base no local de residência do usuário, e poderá estar alocada nos diversos tipos de serviços de atenção à saúde, tais como hospital, Unidades de Pronto Atendimento (UPA), Unidades Básicas de Saúde (UBS), devendo estar vinculada administrativamente ao $\mathrm{SAD}$, não devendo haver superposições de EMAD em uma mesma base territorial ou populacional. Nos casos de municípios com população entre 40 mil e 100 mil habitantes, a população adstrita à EMAD deve ser a totalidade dos habitantes do município. Para dar suporte e complementar as ações de saúde da atenção domiciliar, quando clinicamente indicadas, será designada 1 (uma) EMAP. 5

Com base nesse contexto de atendimento multiprofissional, realiza-se a discussão do atendimento domiciliar de idosos, partindo do cuidado específico dos profissionais da Enfermagem, Medicina e Psicologia.

\section{A inserção do enfermeiro na visita domiciliar}

A análise dos artigos indica que o enfermeiro ocupa um papel central na VD. A relevância de sua atuação se revela por ser coordenador do cuidado e responsável pela sua prestação aos pacientes. A esse respeito, tem se revelado na literatura como profissional fundamental na construção desse tipo de cuidado. ${ }^{5}$

A atuação do enfermeiro na visita domiciliar é influenciada tanto pelo perfil dos pacientes quanto pela lógica peculiar que predomina no domicílio. Ele atende a um perfil diversificado, sendo possível identificar nesta revisão o predomínio de pacientes em cuidados paliativos e idosos, ainda que os artigos analisados tenham evidenciado ações no atendimento a crianças e jovens com necessidades complexas, assim como pessoas com transtorno mental. A revisão

Quadro 1. Modalidades de atenção domiciliar

\begin{tabular}{|c|l|c|}
\hline Modalidade & Usuário & \multicolumn{1}{|c|}{ Equipe } \\
\hline AD1 & $\begin{array}{l}\text { - Problemas de saúde controlados e/ou compensados. } \\
\text { - Dificuldade ou impossibilidade física de locomoção. } \\
\text { - Necessita de cuidados de baixa complexidade, com menos recursos e menor frequência. } \\
\text { - Dentro da capacidade de atendimento da UBS. }\end{array}$ & Equipe de atenção básica \\
\hline AD2 & $\begin{array}{l}\text { - Problemas de saúde, dificuldade ou impossibilidade de locomoção. } \\
\text { - Maior frequência de cuidado, recursos de saúde e acompanhamento contínuo. } \\
\text { - Necessidade de visitas semanais. }\end{array}$ & EMAD + EMAP \\
\hline - Semelhante AD2 em uso de equipamentos/procedimentos especiais. & EMAD + EMAP \\
\hline
\end{tabular}

Fonte: Adaptado de Brasil. ${ }^{3}$ 
dos artigos revelou que enfermeiros realizam ações diversificadas no atendimento domiciliar, tais como: apoio interpessoal, educação em saúde a pacientes, familiares e cuidadores, realização de procedimentos técnicos e supervisão clínica e administrativa. A interação entre enfermeiros e pacientes, familiares e/ou cuidadores se configura como ação fundamental no contexto domiciliar, indicada na maioria das publicações.

A atenção domiciliar realizada pela enfermagem, além de ser uma experiência agregadora na formação e no cuidado, é uma atividade propositora de reflexões e transformações pessoais e profissionais. ${ }^{6}$ Nesse sentido, a visita domiciliária é entendida como método, técnica e instrumento no qual se estabelecem as relações, a escuta qualificada, o vínculo e o acolhimento. É também entendida como unidade de cuidado, estabelecida in loco, no seu cotidiano, no mundo vivido e enfrentado, de acordo com a visão contemporânea de sociedade. É nesse contexto que os profissionais da saúde devem se despir do seu conhecimento e crenças para poder entrar no espaço do outro.

Embora não sendo uma abordagem nova no âmbito da saúde pública brasileira, a visita ocupa um espaço cada vez mais importante. Com a implantação da ESF, a VD passou a ser uma estratégia norteadora que conduz o movimento das relações, da escuta qualificada, do acolhimento e do vínculo profissional-usuário. Tal prática contribui para que as famílias e comunidades tenham condições de se tornarem protagonistas da sua própria produção de saúde e permite conhecer: as condições de vida e habitação das famílias, as relações que estabelecem no ambiente, as condições de adoecimento da família e, consequentemente, facilita o planejamento e o direcionamento das ações, visando à promoção da saúde e ao fortalecimento do autocuidado. $^{7}$

Os resultados deste estudo demonstram, portanto, que o processo de (re)organização pessoal e profissional passa pela desordem, pela autorreflexão e pela superação dos limites do saber instituído. Demonstram, que a persistência, as interações, o diálogo e as discussões teóricas foram fundamentais para transcender as percepções pontuais e lineares, bem como o desenvolvimento da dimensão intersubjetiva.

Conforme os estudos, a visita domiciliar pode/ deve ser considerada uma importante tecnologia para a formação de profissionais humanistas, críticos e reflexivos, pela compreensão da realidade no âmbito individual e coletivo. A visita domiciliar é, em síntese, uma tecnologia de ensino-aprendizagem empreendedora pela possibilidade de contribuir para o desenvolvimento de competências e habilidades relacionais, sociais e políticas para o fortalecimento e consolidação do sistema de saúde nacional. ${ }^{?}$

A transformação das práticas de enfermagem passa, em suma, pela emergência e valorização de novos saberes, dentre eles o saber popular, por uma postura dialógica entre profissional-usuário, por uma abertura conceitual e científica em relação ao modelo biomédico vigente e uma maior corresponsabilidade política e social. Essas transformações são potenciais construtoras de vínculos, aproximando quem oferece o cuidado, nesse caso o cuidado de enfermagem, de quem o recebe, a partir de atitudes solidárias que implicam em colocar-se no nível da outra pessoa e deixar a outra pessoa ser ela mesma. ${ }^{6}$

Os artigos trazem resultados semelhantes em relação à importância e ao cuidado durante as VDs. No entanto, alguns autores ampliam as discussões ao defender que a visita domiciliar favorece o cuidado humano, criativo, sensível e longe da internação hospitalar. ${ }^{8}$ Vários outros estudos evidenciam que apesar de a VD apresentar limitações por ter sido realizada com foco na doença e em torno das práticas curativistas, que tornam secundárias a produção de autonomia e a corresponsabilização das famílias no cuidado à saúde, ela foi concebida como importante instrumento de promoção da intersubjetividade.

A visita domiciliar favorece o acesso às ações e aos serviços de saúde, sendo apontada como instrumento de humanização da atenção à saúde, ao propiciar a construção de novas relações entre usuários e profissionais e a formação de vínculo entre estes ${ }^{9}$. Outro ponto positivo que emergiu nas publicações foi a criação de vínculo, sendo este representado pelos profissionais como um estado de "respeito" e de "confiança" conquistado por eles em relação aos usuários e construído por meio da "convivência" e do "contato" constante, permitido mais por um tempo emocional do que por um tempo cronológico.

\section{A visita domiciliar como um espaço que permite construção de estratégias e ações de cuidado}

O espaço não se limita ao local físico onde ocorre o atendimento, porém apresenta um conceito muito mais amplo em saúde, de momento, intervalo, distância, em que a equipe propicia um ambiente de facilitação para realizar uma intervenção em saúde. Principalmente, é um espaço de diálogo, onde o profissional ultrapassa a questão técnico-científica do cuidado e auxilia na comunicação e compreensão por parte da própria equipe de saúde, da família e do cuidador. Borges, ${ }^{10}$ destaca: 
Para que esse processo ocorra, é preciso que o médico esteja presente a atuante na comunidade, sendo sua formação de tal modo que dê conta de contemplar os problemas de saúde mais prevalentes, relacionando-se com o paciente e sua família e tendo a abertura para aceitar opiniões e condutas, algumas vezes, diversas das que são prescritas.

Além disso, o médico transforma esse espaço físico em uma sala de aula, ensinando e guiando os cuidados para com o paciente e os familiares. Os artigos de Romanholi e Cyrino ${ }^{11}$ e Cerqueira et al. ${ }^{12}$ citam a importância de levar os alunos de medicina nas visitas domiciliares aos idosos, mudando o paradigma antigo da educação médica e criando novos/velhos espaços de ensino-aprendizagem.

Além disso, é um local que permite a implementação e atuação de programas específicos do Ministério da Saúde, sendo um foco de investimento. Dentre eles, podemos citar o Programa Melhor em Casa, em que o médico atua com o foco de reduzir os índices de internações hospitalar e, por conseguinte, os custos, e o Programa de Atenção Domiciliar ao Acamado, específico para pacientes com patologias que lhes limitem ao leito. ${ }^{43}$

Os critérios desses programas são bem específicos e muitos pacientes acabam não se encaixando neles. A grande problemática é a fragilidade da longitudinalidade da atenção básica no cuidado do paciente idoso que ganha alta hospitalar e não consegue adesão nos programas especializados, ficando assim sob responsabilidade da equipe da ESF adscrita. Ainda analisando esse cuidado, Paiva ${ }^{14}$ destaca "[...] a fragilidade da rede para alta e encaminhamento para outro ponto de atenção e a realidade clínica ou administrativa do paciente".

O domicílio do paciente é retratado como o "melhor" espaço de acolhimento onde o médico pode atuar, visto que a escuta do profissional e o cuidado ocorre no local em que o paciente se sente à vontade, propiciando assim uma relação médico-paciente fortalecida.

\section{A importância do médico durante a visita domiciliar}

Notoriamente, o modelo de assistência em saúde modificou-se muito ao longo dos anos no Brasil. Desde o "nascimento" do SUS até a implementação das Estratégias de Saúde da Família (ESF), o papel do médico dentro da equipe foi se ajustando e ocupando lugares e responsabilidades distintas, partindo do cuidado específico e individualizado por distintas especialidades muito segmentadas até chegar à implementação das ESFs. Nessa nova representação, o médico, generalista ou médico de família, assume um modelo de cuidado mais amplo, em que o foco é a prevenção e promoção da saúde, sempre trabalhando de forma multidisciplinar, visando avaliar o paciente de maneira independente e ir agregando atendimentos de outros profissionais geralmente coordenado pelo médico, e interdisciplinar, onde a equipe de profissionais colaboram seguindo o mesmo objetivo e todos dividindo a coordenação do cuidado do paciente. $O$ atendimento não se limita somente à unidade de saúde, mas também ao domicílio do paciente, conhecendo a dinâmica familiar e realizando um cuidado direcionado ao seu contexto. No atendimento ao idoso, essa modalidade tem uma grande importância, pois o local onde ele vive e suas reais capacidades podem ser avaliadas, desde a arquitetura da casa até o seu grau de atividade.

Durante as narrativas, identificam-se distintos papéis do médico, por parte da equipe, do próprio profissional, dos familiares e cuidadores e do pesquisador que acompanha o médico em seu atendimento.

A humanização do médico é um fator importante durante a consulta, visto que ele se aproxima da realidade desse idoso e sua família, saindo do seu "espaço protegido" e entrando no espaço do paciente. Com isso, o idoso vê o médico muito mais como pessoa e se iguala, o que auxilia durante o diálogo. Identifica-se o profissional como observador, analisando a dinâmica do idoso com sua família, com a comunidade, com o próprio espaço físico, o armazenamento dos fármacos, a acessibilidade e o cuidado de forma geral.

Diversos autores ${ }^{15,16,17}$ discutem o papel do médico como gestor do cuidado, discordando apenas na forma da organização desses cuidados, sendo que na grande maioria das vezes o médico é o gestor e delega as funções aos outros profissionais. Teixeira ${ }^{16}$ destaca:

De fato, perante a nova realidade socioeconômica do país, crescentes desafios se colocam ao médico de família, ao qual cada vez mais é exigido um papel ativo, ao nível da gestão de meios/recursos comunitários, e, também, se necessário de defesa do doente na interface de cuidados $[\ldots]$.

Isso demonstra a situação prática da responsabilidade que é proferida ao médico nessa gestão. Contrapondo-se a essa visão médico-centrada, outros trazem a enfermagem e a medicina trabalhando em conjunto, de forma interdisciplinar, para a gestão desses cuidados.

Como discutido previamente, o médico assume um papel de professor, porém chama a atenção que poucos $\operatorname{artigos}^{11,12}$ trouxeram o médico como professor para acadêmicos no contexto da atenção domiciliar, uma vez que a grande maioria trouxe o papel do médico como 
um professor referente aos cuidadores desses idosos dependentes (formal ou informal).

Por fim, em contraste ao primeiro perfil, existe o médico puramente técnico, que não objetiva a aproximação com o paciente de forma exitosa, mantendo a mesma postura de seu consultório, muitas vezes por falta de formação adequada, experiência ou por uma deficitária inserção na comunidade.

Durante a aproximação do médico com a realidade do paciente, muitos fatores que influenciam no cuidado são evidenciados: sociais, culturais e, principalmente, econômicos. Essas questões geram grande discussão no âmbito da saúde pública, pois muitas vezes são barreiras na construção e execução das estratégias em saúde.

A frustração e a impotência são os itens mais discutidos, visto que o médico enfrenta uma realidade difícil, com grandes barreiras culturais, de educação e hábitos complexos que limitam o entendimento das estratégias do cuidado, que o leva a uma grande adaptação de suas ações e uma reorganização das condutas da equipe. A situação socioeconômica é a barreira mais desafiadora, uma vez que o profissional enfrenta limitações e, em diversos momentos, tem que optar por insumos que não são os ideais, mas que são os únicos que no momento estão à disposição.

Todas essas questões fazem com que ocorra um grande sofrimento por parte do profissional, que se sente sobrecarregado com problemas que vão muito além do conhecimento técnico-científico. Esse sofrimento psíquico do profissional é exposto de forma muito objetiva e é citado de forma inversamente proporcional aos anos de experiência na atenção básica.

Romanholi e Cyrino ${ }^{11}$ evidenciam muita dramaticidade nos relatos dos acadêmicos de medicina que realizaram sua prática na atenção domiciliar, como destacado no seguinte trecho:

[...] pode-se perceber certo constrangimento na realização das primeiras visitas domiciliares, tanto por parte dos alunos como pelas próprias famílias. O trabalho realizado pela disciplina de psicologia médica tem apoiado este primeiro encontro. Alguns alunos apresentam enorme ansiedade por terem de assumir este chegar à casa de um estranho, e nem sempre o aluno está pronto para mobilizar sua capacidade de empatia $[\ldots] .{ }^{11}$

Aspectos positivos são fortalecidos durante essa prática. A empatia e a compaixão são temas encontrados nos relatos, em que o profissional é capaz de colocar-se no lugar do outro e manter essa relação de ajuda a outrem, de forma técnica, mesmo que em alguns momentos haja excesso, transferência/ contratransferência com impacto negativo.

\section{O olhar da psicologia no contexto da visita domiciliar}

Cada vez mais se percebe o aumento do número de idosos procurando atendimento psicológico. Percebe-se aí que surge um novo nicho no mercado de trabalho da psicologia. Os motivos são diversos: desde a busca da aceitação da idade e, consequentemente, as limitações que muitas vezes ela acomete até a busca familiar no auxílio do manejo com o idoso que, não raro, se encontra demenciado e com dificuldades no convívio familiar, social e emocional. Em muitos relatos se observa o auxílio psicológico aos cuidadores desses idosos. ${ }^{8,18}$

De forma geral, a visita domiciliar pode contribuir para a prevenção da doença, promoção da saúde, assistência para doenças já instaladas, liberação de leitos hospitalares, atendimento digno a pessoas que não podem se locomover até os hospitais, sendo uma importante ferramenta para auxiliar as famílias no desenvolvimento da autonomia no processo saúdedoença, permitindo aos profissionais de saúde maior compreensão da realidade do sujeito e suas relações, além dos cuidados paliativos do paciente. ${ }^{19}$

Em um estudo sobre a assistência domiciliar ao idoso, ${ }^{20}$ esta foi estatisticamente associada à história prévia de acidente vascular cerebral, à presença de sinais de demência e à incapacidade para as atividades da vida diária. A família foi responsável por $75 \%$ das solicitações de cuidado.

O objetivo do psicólogo durante a atenção domiciliar é capacitar as famílias a utilizarem seus recursos para a resolução dos problemas enfrentados, garantindo maior autonomia aos sujeitos envolvidos. Entretanto, tal modalidade não é tradicionalmente ensinada nos cursos de psicologia, o que traz mais dúvidas e insegurança para a prática profissional. ${ }^{18}$ Não podemos partir do pressuposto de que todos os pacientes com doenças crônicas e dependentes necessitem de tratamento psicológico, assim como seus cuidadores e demais familiares, visto que muitos se valem de mecanismos de defesa eficazes para lidar com a situação em que se encontram. Percebe-se com frequência a racionalização em relação ao que é vivenciado e observa-se o importante papel suportivo desempenhado pela religião na vida dessas pessoas. Além disso, nem sempre a presença do psicólogo na casa é requerida pelo próprio paciente. ${ }^{21}$

O cuidador familiar necessita e, muitas vezes, solicita para si o atendimento, pois a ausência de lazer aliada ao confinamento no ambiente do cuidar constante leva o cuidador familiar, não raro, a sentir-se sobrecarregado emocional e fisicamente, logo levando-o ao esgotamento. ${ }^{22}$ Há casos em que o médico de família ou algum outro profissional percebe o desgaste 
desse cuidador e solicita a averiguação da existência de demanda de paciente e/ou familiares para a realização do tratamento. ${ }^{21} \mathrm{O}$ envolvimento da família é primordial ao longo de todo o processo do adoecimento e tratamento, principalmente quando esse paciente passa a ser cuidado em seu domicílio. $O$ trabalho voltado aos cuidadores de pacientes paliativos é desgastante, e a demanda em abrir um espaço para esses familiares e cuidadores serem ouvidos, de maneira menos técnica e mais humana, podendo colocar seus sentimentos e expectativas sem sentimento de culpa ou medo por se expressarem, torna-se primordial para o melhor acompanhamento de todo o processo do enfermo. ${ }^{19}$

No âmbito da atenção básica, nos municípios que dispõem desse serviço, o psicólogo que atende ao público idoso no domicílio está inserido em diversas configurações da $A B$. Já em municípios de pequeno porte, ele encontra-se em algumas ESFs ou em centros de especialidades. A grande maioria das cidades possui o profissional nos Centros de Atenção Psicossociais (CAPS), nos Núcleos de Apoio à Saúde da Família (NASF) ou nas equipes que conformam a EMAP do Programa Melhor em Casa. ${ }^{4}$

Nesse panorama, o único serviço específico e que possui profissionais que realizam somente $\mathrm{o}$ atendimento domiciliar é o das equipes do Melhor em Casa, que concentra o maior número de atendimentos domiciliares ao público idoso e sua família. Ressalta-se que no âmbito da $A B$, o atendimento domiciliar deve ser solicitado pelo médico de família ou clínico da equipe ou pelo enfermeiro responsável, que após fazer a avaliação do paciente realiza o pedido de atendimento psicológico ao paciente e sua família.

A psicologia social é muito abordada durante a VD com idosos na $\mathrm{AB}$, demonstrando a amplitude desse atendimento e seu impacto naquela sociedade, e não só no núcleo familiar do paciente. Atualmente, as academias estão mudando os paradigmas na formação do psicólogo, e nesse processo, a atenção domiciliar no âmbito da saúde pública está ganhando espaço:

Diante disso, emerge a necessidade de se refletir sobre a formação que os estudantes de psicologia recebem na graduação e como irão lidar com a demanda do mercado de trabalho atual - em que felizmente ampliam-se as estratégias em atenção básica de saúde, considerando a sua atuação, comprometimento, responsabilidade em relação ao bem-estar e qualidade de vida dos sujeitos e as demandas sociais. Dificilmente uma formação abarca todas as possibilidades de intervenção de um futuro profissional, entretanto a formação tradicional em psicologia distancia ainda mais os estudantes do futuro que os aguarda. Por outro lado, viver a experiência da Visita Domiciliar traz um amadurecimento pelo contato direto com a realidade não só psicológica, mas de saúde e social num contexto mais amplo. ${ }^{23}$
Diferentemente de outros profissionais, o psicólogo encontra no domicílio do paciente um espaço no qual sente-se mais confortável e apto para uma intervenção em saúde, com o paciente e seus familiares. Diversos trabalhos ${ }^{22,23}$ demonstram que o papel da psicologia na VD fortalece o elo do paciente com toda a equipe multiprofissional.

Ademais, Laham ${ }^{21}$ fala da importância que o profissional de psicologia possui em conhecer os medicamentos em uso e sobre a adesão ao tratamento, de modo que possa influenciar a relação com a equipe e os familiares e permanecer alerta sobre implicações orgânicas, compreendendo sempre o quadro clínico do paciente.

\section{CONSIDERAÇÕES FINAIS}

Salienta-se, enfim, a importância do desenvolvimento de novas pesquisas nesse campo de saberes, tendo em vista que foram encontrados poucos estudos que discutem a importância da visita familiar no processo de formação profissional. Ainda, a grande maioria dos trabalhos discutidos foram pesquisas qualitativas, assim prevalecendo o "olhar" do pesquisador, o que sugere que mais estudos quantitativos sobre a temática devem ser estimulados, vindo a complementar os debates científicos.

Foi encontrada reduzida literatura no âmbito da medicina e da psicologia durante a visita domiciliar a idosos na atenção básica. $\mathrm{Na}$ área da enfermagem, os artigos foram mais específicos no papel do enfermeiro na gestão do cuidado.

Embora não sendo uma abordagem nova no âmbito da saúde pública brasileira, a visita familiar ocupa um espaço cada vez mais importante. A ESF passou a ser uma estratégia norteadora que conduz o movimento das relações, da escuta qualificada, do acolhimento e do vínculo profissional-usuário.

As transformações das práticas dos profissionais da saúde passam, em suma, pela emergência e valorização de novos saberes, dentre eles o saber popular, por uma postura dialógica entre profissional-usuário, por uma abertura conceitual e científica em relação ao modelo biomédico vigente e uma maior corresponsabilidade política e social. Essas transformações são potenciais construtoras de vínculos, aproximando quem oferece o cuidado, nesse caso o cuidado no domicílio. Salientam-se a partir de atitudes solidárias que implicam em colocar-se no nível da outra pessoa e deixar a outra pessoa ser ela mesma.

Enfim, evidencia-se a importância de novas pesquisas, tendo em vista a multidisciplinaridade, as quais discutem a importância da visita familiar no processo dos serviços de saúde. 


\section{REFERÊNCIAS}

1. Brasil. Ministério da Saúde. Secretaria de Atenção à Saúde. Manual de monitoramento e avaliação da atenção domiciliar/Melhor em Casa [Internet]. Departamento de Atenção Básica. Brasília: Coordenação-Geral de Atenção Domiciliar; 2016. [Acesso em 12 jul. 2018]. Disponível em: http://bvsms.saude.gov.br/bvs/publicacoes/manual_ monitoramento_avaliacao_programa.pdf

2. Backes DS, Grando MK, Gracioli MA, et al. Theoretical and practical experience with an innovative approach to nursing education. Escola Anna Nery. 2012;16(3):597-602. http:// dx.doi.org/10.1590/S1414-81452012000300024

3. Lopes WO, Saupe R, Massaroli AA. Visita domiciliar: tecnologia para o cuidado, o ensino e a pesquisa. Ciência Cuidado Saúde. 2008;7(2):241-7. http://dx.doi.org/10.4025/ cienccuidsaude.v7i2.5012

4. Cunha CLF, Gama ME. A visita domiciliar no âmbito da atenção primaria em saúde. In: Malagutti W, org. Assistência domiciliar - atualidades da assistência de enfermagem. Rio de Janeiro: Rubio; 2012. p. 37-48.

5. Brasil. Ministério da Saúde. Secretaria de Atenção à Saúde. Departamento de Atenção Básica. Caderno de atenção domiciliar [Internet]. Departamento de Atenção Básica. Brasília: Ministério da Saúde; 2013. [Acesso em 12 jul 2018]. Disponível em: http://189.28.128.100/dab/docs/ portaldab/publicacoes/cad_vol2.pdf

6. Brasil. Ministério da Saúde. Secretaria de Atenção à Saúde. Departamento de Atenção Básica. Manual instrutivo do Melhor em Casa [Internet]. Brasília: Ministério da Saúde; 2015. [Acesso em 12 jul. 2018]. Disponível em: http://189. 28.128.100/dab/docs/geral/cartilha_melhor_em_casa.pdf

7. Oliveira MAC, Pereira IC. Primary Health Care essential attributes and the Family Health Strategy. Rev Bras Enferm. 2013;66(2):158-64. http://dx.doi.org/10.1590/S003471672013000700020

8. Kebian LVA, Pena DA, Ferreira VA, et al. Health promotion and nurses health practices during home visits. Journal APS. 2012;15(1):92-100.

9. Cruz MM, Bourget MM. Home visiting in the Family Health Strategy: investigating families' perceptions. Saúde Sociedade. 2010;19(3):605-13. http://dx.doi.org/10.1590/ S0104-12902010000300012

10. Borges R, D'Oliveira AFPL. The medical home visit as a space for interaction and communication in Florianopolis Santa Catarina. Interface - Comunic, Saúde, Educ. 2011; 15(37):461-72.

11. Romanholi RMZ, Cyrino EG. Home visits in doctors' training: from conception to the challenge of practice.
Interface - Comunic, Saúde, Educ. 2012;16(42):693-705. http://dx.doi.org/10.1590/S1414-32832012000300009

12. Cerqueira ATAR, Torres AR, Martins STF, et al. Um estranho à minha porta: preparando estudantes de medicina para visitas domiciliares. Revista Brasileira de Educação Médica. 2009;33(2):276-81. http://dx.doi.org/10.1590/ S0100-55022009000200016

13. Freitas IBA, Meneghel ST, Sell L. The construction of care by the health team and the caretaker within a home-care program for bedridden patients in Porto Alegre (RS, Brazil). Ciênc Saúde Coletiva. 2011;16(1):301-10. http://dx.doi. org/10.1590/S1413-81232011000100032

14. Paiva PA, Silva YC, Soares NF et al. Serviços de Atenção Domiciliar: critérios de elegibilidades, inclusão, exclusão e alta. Rev Bras Promoç Saúde. 2016;29(2):244-52. http:// dx.doi.org/10.5020/18061230.2016.p244

15. Amthauer C, Falk JW. Discursos dos profissionais de saúde da família na ótica da assistência à saúde do idoso. Rev Fund Care Online. 2017;9(1):99-105. http://dx.doi. org/10.9789/2175-5361.2017.v9i1.99-105

16. Teixeira D. Gestão de cuidados ao idoso dependente: relato de um caso. Rev Bras Med Fam Comunidade. 2016;11(38): 1-7. https://doi.org/10.5712/rbmfc11(38) 1103

17. Boas PJFV, Souza ML, Augusto MC, et al. Acompanhamento domiciliar de idoso de unidade de saúde da família de Botucatu. Rev Bras Educ Med. 2012;36(1):161-5. http:// dx.doi.org/10.1590/S0100-55022012000200022

18. Pietroluongo APC, Resende TIM. Visita domiciliar em saúde mental: o papel do psicólogo em questão. Psicologia: Ciência e Profissão. 2007;27(1):22-31. http://dx.doi.org/10.1590/ S1414-98932007000100003

19. Faria AA, Aparecido AM, Cruz GL, et al. Cuidando de quem cuida - o papel do psicólogo com cuidadores de pacientes paliativos. Revista Saúde em Foco. 2017;1(9).

20. Thume E, Facchini LA, Tomasi E, et al. Home health care for the elderly: associated factors and characteristics of access and health care. Rev Saúde Pública. 2010;44(6):1102-11. http://dx.doi.org/10.1590/S0034-89102010005000038

21. Laham CF. Peculiaridades do atendimento psicológico em domicílio e o trabalho em equipe. Psicologia hospitalar 2004;2(2).

22. Pedreira LC, Oliveira AMS. Cuidadores de idosos dependentes no domicílio: mudanças nas relações familiares. Rev Bras Enferm. 2012;65(5):730-36. http://dx.doi.org/ 10.1590/S0034-71672012000500003

23. Aron M, Santos NCD. The Psychologist Performance in the household visit. RG\&PP. 2015;5(1):155-67.

\section{AUTORES:}

IBRAHIM CLÓS MAHMUD <ibrahim mahmud@hotmail.com>

Médico. Mestrando em Gerontologia Biomédica na Pontifícia Universidade Católica do Rio Grande do Sul (PUCRS) e especializando em Geriatria Clínica (PUCRS); especialista em Saúde da Família (UFCSPA). Bolsista CAPES-PROEX

(D) orcid.org/0000-0002-2631-2964

CARLA VIERO KOWALSKI <carlakowalski25@gmail.com>

Enfermeira. Doutoranda em Gerontologia Biomédica (PUCRS); mestre em Saúde Coletiva (UNISINOS); especialista em Cuidados Intensivos (UNIFRA) e Educação Profissional em Enfermagem (ENSPSA). Bolsista CAPES-PROEX.

BRUNA THAíSE LAVAGNINI <bruna lavagnini@hotmail.com>

Médica. Especialista em Saúde da Família (UFCSPA).

KARINA LAUX SCHUTZ < karina@petterapeuta.com.br>

Psicóloga. Pet Terapeuta. Mestranda em Gerontologia Biomédica (PUCRS); especialista em Terapia Cognitivo-Comportamental (FACCT/WP). Bolsista CAPES-PROEX. Claus Dieter StOBÄUS <stobaus@pucrs.br>

Médico. Mestre e Doutor em Educação (UFRGS). Docente da PUCRS.

NEWTON LUIZ TERRA <terranl@pucrs.br>

Médico. Geriatra. Mestre em Educação (PUCRS) e Doutor em Gerontologia Biomédica (PUCRS). Diretor do Instituto de Geriatria e Gerontologia e Docente da PUCRS. 